\title{
EFEKTIVITAS PELATIHAN OPTIMALISASI PERAN TOKOH MASYARAKAT TERHADAP PENGETAHUAN TENTANG DIABETES MELITUS DAN PERANNYA DI DESA BABAKAN KECAMATAN KARANGLEWAS
}

\section{EFFECTIVENESS OF TRAINING ON OPTIMIZING THE ROLE OF COMMUNITY LEADERS AND RELIGIOUS LEADERS FOR KNOWLEDGE OF DIABETES MELLITUS AND ITS ROLE IN BABAKAN VILLAGE, SUBDISTRICT KARANGLEWAS}

\author{
Arif Kurniawan, Arrum Firda Ayu M, Dian Anandari, Windri Lesmana Rubai \\ Jurusan Kesehatan Masyarakat, Fakultas Ilmu-Ilmu Kesehatan \\ Universitas Jenderal Soedirman
}

\begin{abstract}
This study aims to determine the effectiveness of training with lecture methods, discussion and practice in increasing knowledge about diabetes mellitus, and knowledge about the role of community leaders in preventing diabetes mellitus. This study uses a quasi-experimental one group pre-test post test without control design. The population in this study are community leaders and religious leaders in the village of Babakan. The sample of this study was a total population of 32 people. The results showed the training was not effective in increasing knowledge about diabetes mellitus, but effectively increasing knowledge about the role of community leaders and religious leaders in prevention diabetes mellitus in Babakan village. The results of differences in knowledge about the role of community leaders and religious leaders in management showed an increase in the mean pretest value $(74.8)$ to 81.4. Statistical results showed a significant difference $(p=0.021)$ the value of knowledge about the role of community leaders and religious leaders in the management of Type 2 Diabetes Mellitus before and after training. The recommendation of this research is the village head to improve the role of community leaders in the management of type 2 diabetes mellitus.
\end{abstract}

Keywords: Training, Role of Community Leaders, Diabetes Mellitus Type 2

\section{ABSTRAK}

Penelitian ini bertujuan mengetahui efektifitas pelatihan dengan metode ceramah, diskusi dan praktek dalam peningkatan pengetahuan tentang diabetes melitus, dan pengetahuan tentang peran tokoh masyarakat dalam mencegah diabetes melitus. Penelitian ini menggunakan metode quasi experiment one group pre test-post test without control design. Populasi dalam penelitian ini adalah tokoh masyarakat dan tokoh agama di desa Babakan. Sampel penelitian ini adalah total populasi sejumlah 32 orang. Hasil penelitian menunjukkan pelatihan tidak efektif meningkatkan pengetahuan tentang diabetes melitus, namun efektif meningkatkan pengetahuan tentang peran tokoh masyarakat dan tokoh agama dalam mencegah diabetes melitus di desa Babakan. Hasil perbedaan pengetahuan tentang peran tokoh masyarakat dan tokoh agama dalam pengelolaan menunjukkan ada peningkatan nilai mean pre test $(74,8)$ menjadi 81,4 . Hasil statistik menunjukkan adanya perbedaan secara signifikan $(\mathrm{p}=0,021)$ nilai pengetahuan tentang peran tokoh masyarakat dan tokoh agama dalam pengelolaan Diabetes Melitus Tipe 2 sebelum dan sesudah pelatihan. Rekomendasi penelitian ini kepala desa meningkatkan pembinaan peran tokoh masyarakat dalam pengelolaan diabetes mellitus type 2 .

Kata kunci : Pelatihan, Peran Tokoh Masyarakat, Diabetes Melitus Tipe 2

\section{PENDAHULUAN}

$$
\text { Diabetes Melitus (DM) }
$$

merupakan penyakit gangguan metabolik menahun akibat pankreas tidak memproduksi cukup insulin atau tubuh tidak dapat menggunakan insulin yang diproduksi secara efektif. Akibatnya terjadi peningkatan konsentrasi glukosa di dalam darah (hiperglikemia) (Pusdatin Kemenkes, 2014). Beberapa program pemerintah di Indonesia, salah satunya prioritas program keluarga sehat untuk pengendalian penyakit tidak menular adalah menurunkan prevalensi DM. (P2PL, 
2015). Tujuan program pengendalian DM di Indonesia adalah terselenggaranya pengendalian faktor risiko untuk menurunkan angka kesakitan, kecacatan dan kematian yang disebabkan DM. Pengendalian DM lebih diprioritaskan pada pencegahan dini melalui upaya pencegahan faktor risiko DM yaitu upaya promotif dan preventif (Kemenkes, 2015)

Estimasi terakhir IDF, terdapat 382 juta orang yang hidup dengan DM di dunia pada tahun 2013. Pada tahun 2035 jumlah tersebut diperkirakan akan meningkat menjadi 592 juta orang. Diperkirakan dari 382 juta orang tersebut, 175 juta diantaranya belum terdiagnosis, sehingga terancam berkembang progresif menjadi komplikasi tanpa disadari dan tanpa pencegahan (Pusdatin Kemenkes, 2014). Berdasarkan proyeksi World Health Organization, diperkirakan bahwa dalam kurun waktu 30 tahun (1995-2025), jumlah penderita diabetes di negara berkembang akan meningkat sebesar $170 \%$. Dari persentase tersebut, jumlah penderita diabetes di Indonesia akan meningkat dari 5 juta penderita menjadi 12 juta penderita yang akan termasuk dalam daftar 10 negara dengan jumlah penderita diabetes terbesar (Healthy Choice, 2002).

Di Indonesia prevalensi DM berdasarkan jawaban pernah didiagnosis dokter sebesar 1,5\%. DM berdasarkan diagnosis atau gejala sebesar 2,1 \%. Proporsi penduduk $\geq 15$ tahun dengan diabetes mellitus (DM) adalah 6,9 persen. kecenderungan prevalensi DM berdasarkan wawancara tahun 2013 adalah 2,1 persen (Indonesia), lebih tinggi dibanding tahun $2007(1,1 \%)$. Proporsi DM di Indonesia sebesar 6,9 persen dengan proporsi DM pada perempuan cenderung lebih tinggi. Telah terjadi pergeseran antara proporsi penderita DM di wilayah perkotaan dan perdesaan. Riskesdas tahun 2007 proporsi penderita DM lebih tinggi pada masyarakat perkotaan dibandingkan masyarakat perdesaan. Pada masyarakat perdesaan $(5,8 \%)$ dan masyarakat perkotaan $(14,7 \%)$, namun Riskesdas tahun 2013 proporsi DM mengalami pergeseran, dimana prevalensi di perdesaan lebih tinggi $(7,0 \%)$ sedangkan di perkotaan $(6,8 \%)$ (Riskesdas, 2013).

Prevalensi DM di Jawa Tengah berdasarkan diagnosis dokter sebesar 1,6 $\%$, sedangkan DM berdasarkan diagnosis atau gejala sebesar 1,9 persen. Penemuan kasus baru DM di Provinsi Jawa Tengah pada tahun 2014 ID DM sebanyak 6.427 kasus dan ND DM sebanyak 96.431 kasus. Penemuan kasus baru DM di Kabupaten Banyumas pada tahun 2014 ID DM sebanyak 306 kasus dan ND DM sebanyak 1.878 kasus (Dinkes Kabupaten Banyumas, 2015).

Pengelolaan DM berbasis komunitas perlu digerakkan untuk menanggulangi masalah DM. Peran komunitas di dalam masyarakat lebih 
banyak dimainkan oleh tokoh masyarakat.

Tokoh masyarakat juga disebut elit masyarakat. Tokoh masyarakat sendiri dibedakan menjadi tokoh masyarakat formal dan informal. Mereka bertindak mewakili masyarakat atau yang mengatasnamakannya (Lipset dan Solari, 2001). Penelitian Jewell juga menyatakan bahwa peran tokoh masyarakat memotivasi mereka dalam mengelola DM yang dideritanya (Jewel et.al, 2017). Berdasarkan penelitian Maqfiroch (2017) ditemukan bahwa tokoh agama dan tokoh masyarakat yang berada di perdesaan mempunyai dukungan lebih rendah dalam mendukung pencegahan DM. Hasil penelitian Maqfiroch (2018) menunjukkan bahwa pengetahuan tokoh agama dan tokoh masyarakat di wilayah perdesaan di wilayah Puskesmas Karanglewas meliputi Desa Jipang, Desa Singosari, dan Desa Babakan masih rendah, dan belum optimalnya peran tokoh masyarakat sebagai penyuluh, peran tokoh masyarakat sebagai penggerak, peran tokoh masyarakat sebagai motivator, peran tokoh masyarakat sebagai katalisator, serta peran tokoh masyarakat sebagai teladan dalam pengelolaan diabetes mellitus di wilayah perdesaan Banyumas. Penelitian ini bertujuan mengetahui efektifitas intervensi pelatihan optimalisasi peran tokoh masyarakat dalam mengelola Diabetes Mellitus di desa Babakan kecamatan Karanglewas.

\section{METODE}

Tempat penelitian di desa Babakan kecamatan Karanglewas Kabupaten Banyumas. Populasi penelitian ini adalah tokoh masyarakat di desa Babakan. Sampel penelitian yang digunakan adalah total populasi sejumlah 32 orang. Metode: Quasi Ekspreminen dengan desain penelitian yang digunakan adalah bentuk one group pre test-post test design. Tidak ada kelompok pembanding (kontrol) tetapi dilakukan observasi pertama (pre-test) sebelum pemberian intervensi dan dilakukan post test. Intervensi yang dilakukan adalah pelatihan optimalisasi peran tokoh masyarakat dan tokoh agama dalam mengelola diabetes melitus tipe 2 dengan metode ceramah, diskusi, dan praktek. Pelatihan dilakukan selama 16 jam. Materi yang diberikan adalah pengertian dan pencegahan diabetes melitus tipe 2, dan peran tokoh masyarakat dalam mengelola diabetes melitus type 2 di desa. Penelitian dilakukan melalui tiga tahap yaitu sebelum intervensi, intervensi, dan sesudah intervensi. Evaluasi intervensi menggunakan pre test dan post test design. Variabel yang diukur adalah pengetahuan tentang pengetahuan tentang diabetes melitus tipe 2 dan peran tokoh masyarakat dalam mengelola diabetes melitus di desa dengan jawabannya adalah ya atau tidak (benar dan salah). Jawaban yang benar adalah skor 1 dan jawaban yang salah 
adalah skor 0 . Jumlah pertanyaan pengetahuan adalah 16 sehingga skor minimal adalah $(0 / 16) \times 100=0$, dan skor maksimal adalah (16/16) x $100=100$. Analisis perbedaan pengetahuan tentang diabetes melitus tipe 2 dan peran tokoh masyarakat sebelum dan sesudah intervensi menggunakan Paired $\mathrm{T}$ Test dalam software SPSS versi 16. Keterbatasan penelitian ini adalah keterpaparan informasi kesehatan dari sumber media elektronik dan media cetak yang tidak bisa dihindari.

\section{HASIL DAN PEMBAHASAN}

1. Karakteristik Responden

Hasil penelitian menunjukkan sebagian besar responden berjenis kelamin perempuan sebesar $87,5 \%$ (28 orang) dan sebagian kecil berjenis kelamin laki-laki $12,5 \%$ (4 orang). Tokoh masyarakat dalam penelitian ini meliputi warga yang memiliki pengaruh dalam bidang kesehatan di masyarakat, sehingga sebagian besar adalah perempuan.

Tabel 1. DIstribusi responden penelitian berdasarkan Jenis Kelamin

\begin{tabular}{lcc}
\hline Jenis Kelamin & n & \% \\
\hline Laki-laki & 4 & 12.5 \\
\hline Perempuan & 28 & 87.5 \\
\hline
\end{tabular}

2. Pengetahuan Tentang Diabetes

Melitus Tipe 2 Tokoh Masyarakat dan

Tokoh Agama di Desa Babakan

Tabel 4. Perbandingan skor total jawaban Pre-test dan Post-test Pengetahuan DM

\begin{tabular}{|c|c|c|c|c|c|}
\hline \multirow[t]{2}{*}{ Skor Jawaban } & \multicolumn{2}{|c|}{ Kelompok } & \multirow[t]{2}{*}{$95 \% \mathrm{CI}$} & \multirow{2}{*}{$\begin{array}{c}\text { Std. } \\
\text { Deviation }\end{array}$} & \multirow[t]{2}{*}{$P$ Value } \\
\hline & Pre-test & Post Test & & & \\
\hline Mean+Std & $75.6875 \pm 11.380$ & $76.281 \pm 10.380$ & $-5.7594 ;$ & 14.327 & 0.816 \\
\hline Median & $78 . \overline{0} 0$ & 75.00 & 4.571 & & \\
\hline $\begin{array}{l}\text { Range (min- } \\
\text { max) }\end{array}$ & $50.00-94.00$ & $56.00-94.00$ & & & \\
\hline
\end{tabular}

Tabel diatas menunjukkan bahwa ada peningkatan nilai rata-rata (mean) pengetahuan tentang Diabetes Melitus tipe 2 dari 75,68 (hasil pre test) menjadi 76,28 (hasil Post test). Nilai minimum pengetahuan tentang Diabetes Melitus mengalami peningkatan dari 50,0 (hasil pre test) menjadi 56,0 (hasil Post test). Hasil uji statistik dengan paired T-test menunjukkan tidak ada perbedaan pengetahuan tentang Diabetes Melitus tipe 2 dengan nilai signifikansi $(\mathrm{p}=0,816)$.

Tidak adanya perbedaan pengetahuan tentang Diabetes Mellitus tipe 2 sebelum 
dan sesudah pelatihan, disebabkan karena pengetahuan kelompok intervensi sudah baik tentang Diabetes Mellitus Tipe 2, dan peningkatan yang terjadi tidak signifikan pada sebagian besar responden.

Hasil penelitian ini tidak sesuai dengan hasil penelitian Isnaini (2015) tentang pengaruh pemberian edukasi Diabetes Melitus terhadap pengetahuan dan sikap ibu-ibu Aisyiah yang menunjukkan terdapat perbedaan yang bermakna tingkat pengetahuan sebelum dan sesudah diberikan edukasi penyakit Diabetus Mellitus dengan nilai $\mathrm{p}=0.00$.

$$
\text { Penelitian Surya }
$$

menunjukkan bahwa terdapat pengaruh konseling terhadap peningkatan pengetahuan pasien Diabetes Mellitus tipe 2 ( $\mathrm{p}$ Value $0,000<0,05)$ setelah dilakukan intervensi dengan program kontrol di Puskesmas Kopelma Darussalam Banda Aceh, lebih spesifik didapatkan konseling pada pengetahuan pola makan berpeluang $5,59 \%$ untuk berhasil meningkatkan pengetahuan.

Hasil penelitian ini juga tidak sejalan dengan penelitian Supit (2018) yang menunjukkan bahwa pemberian edukasi dengan metode video dan Focus Group Disscusion (FGD) mampu meningkatkan nilai mean pengetahuan responden sebelum dan sesudah intervensi penelitian dengan uji t berpasangan (paired t-test) dengan $\alpha 0.05$ dan berdasarkan hasil uji diperoleh $\mathrm{p}=0.000$ yang berarti $\mathrm{p}<\alpha$ (0.05)

Hasil penelitian sebenarnya sudah ada perbedaan antara nilai mean pengetahuan tentang diabetes melitus sebelum intervensi $(75,68)$ dan sesudah intervensi $(76,28)$, namun setelah diuji dengan paired $\mathrm{t}$ test tidak menunjukkan perbedaan yang signifikan. Apabila dibandingkan dengan penelitian sebelumnya ada kemungkinan metode ceramah dan tanya jawab tidak dapat signifikan menaikan nilai mean pengetahuan tentang diabetes melitus dibandingkan dengan metode video dan FGD. Hal ini juga terjadi pada penelitian Maghfiroch (2018) yang menunjukkan bahwa pelatihan tidak efektif dalam peningkatan peran kader yaitu peningkatan pengetahuan, sikap dan ketrampilan kader sebagai pendamping ibu hamil.

3. Pengetahuan Tentang Peran Tokoh Masyarakat dan Tokoh Agama dalam Pengelolaan Diabetes Melitus Tipe 2

4. Tabel 5. Perbandingan Skor Pre-test dan Post-test pengetahuan tentang peran tokoh

\begin{tabular}{|c|c|c|c|c|c|}
\hline \multirow{2}{*}{ Skor Jawaban } & \multicolumn{2}{|c|}{ Kelompok } & \multirow{2}{*}{$95 \% \mathrm{CI}$} & \multirow{2}{*}{$\begin{array}{c}\text { Std. } \\
\text { Deviation }\end{array}$} & \multirow{2}{*}{$P$ Value } \\
\hline & Pre-test & Post Test & & & \\
\hline Mean+Std & $74.843 \pm 14.727$ & $81.406 \pm 9.178$ & $-12.065 ;-$ & 15.263 & 0.021 \\
\hline Median & 80.00 & 85.00 & 1.059 & & \\
\hline Range (min-max) & $25.00-90.00$ & $55.00-95.00$ & & & \\
\hline
\end{tabular}


Arif Kurniawan, Efektivitas Pelatihan Tokoh Masyarakat Terhadap Pengetahuan Tentang Diabetes Melitus 14

Hasil perbedaan pengetahuan tentang peran tokoh masyarakat dan tokoh agama dalam pengelolaan menunjukkan ada peningkatan nilai mean pre test $(74,8)$ menjadi 81,4. Hasil statistik menunjukkan adanya perbedaan secara signifikan $(\mathrm{p}=$ $0,021)$ nilai pengetahuan tentang peran tokoh masyarakat dan tokoh agama dalam pengelolaan Diabetes Melitus Tipe 2 sebelum dan sesudah pelatihan.

Hasil penelitian ini sejalan dengan penelitian Sari (2018) bahwa ada perbedaan signifikan pada self efficacy pada kader sebelum dan sesudah pelatihan, namun tidak ada perbedaan signifikan pada pengetahuan tentang diabetes melitus. Penelitian ini menggunakan intervensi pelatihan pada kader menggunakan metode promosi kesehatan. Penelitian Ernawati (2012) juga menunjukkan pelatihan manajemen diabetes pada kader kesehatan dapat meningkatkan pengetahuan manajemen diabetes secara bermakna $(p=$ $0,001 ; \alpha=0,05)$.

Hal ini sejalan dengan hasil yang diperoleh oleh Nursiswati (2015), dimana dampak program pemberdayaan kader kesehatan dan masyarakat dalam manajemen self care DM ini adalah adanya Peningkatan kemampuan penderita DM dalam self care management penyakitnya. Tampak pula adanya peningkatan pengetahuan kader dan kepala keluarga dalam managemen DM yang selanjutnya diharapkan mampu meningkatkan kualitas hidup penderita DM

\section{SIMPULAN DAN SARAN}

Peningkatan pengetahuan tentang Diabetes Melitus Tipe 2 sebelum dan sesudah pelatihan, namun tidak ada perbedaan secara signifikan. Peningkatan pengetahuan tentang peran tokoh masyarakat dan tokoh agama dalam pengelolaan Diabetes Melitus tipe 2 sebelum dan sesudah pelatihan, dan ada perbedaan secara signifikan. Saran dalam penelitian ini adalah kepala desa babakan meningkatkan pembinaan peran tokoh masyarakat dalam pengelolaan Diabetes Mellitus Type 2.

\section{DAFTAR PUSTAKA}

Data Kasus Diabetes Mellitus. 2015. Dinas Kesehatan Kabupaten Banyumas.

Ernawati,2012. Peningkatan Pengetahuan dan Ketrampilan Manajemen Diabetes Melalui Pelatihan Manajemen Diabetes Pada Kader Kesehatan, Jurnal Keperawatan Indonesia Vol 15 No 2.

Healthy Choice. 2002. Insulin Serat Makanan Istimewa (edisi I). Jakarta : Majalah Healthy Choice.

Isnaini N, Hikmawati I, 2015. Upaya Preventif Pemberian Edukasi Diabetus Melitus PengaruhnyaTerhadap Pengetahuan dan Sikap Ibu-Ibu Aisyiah. Medisains. Jurnal Ilmiah Ilmu-Ilmu Kesehatan Vol XIII No 1 April 2015

Jewell et al. 2017. Group participants experiences of a patient directed group-based 
education program for the management of type 2 diabetes mellitus, https://doi.org/10.1371/journal.pone. $\underline{0177688}$

Kementrian Kesehatan Republik Indonesia. 2015. Pusat Data dan Informasi Kementrian Kesehatan RI.

Konsensus DM Tipe 2 di Indonesia. 2015. Jakarta : Pengendalian Penyakit dan Penyehatan Lingkungan.

Lipset dan Solari. 2001. Consensus and Conflict Essay In Politics Sociology. New Jersey. Oxfort Univesity Press.

Maqfiroch A, Gamelia E, dan Masfiah S. 2017. Studi Komparasi Perilaku Pencegahan Diabetes Mellitus antara Wilayah Perdesaan dan Perkotaan Kabupaten Banyumas. Laporan Penelitian Dana BLU Unsoed. Universitas Jenderal Soedirman

Maqfiroch A, Kurniawan A, dan Masfiah S. 2018. Analisis Kesiapan Tokoh Masyarakat dalam Pengelolaan Diabetes Mellitus Tipe 2 Kawasan Perdesaan Kabupaten Banyumas. Laporan Penelitian Dana BLU Unsoed. Universitas Jenderal Soedirman

Maghfiroch AFA, Gamelia E, dan Masfiah S, 2018. Efektifitas Pelatihan dalam Peningkatan Peran Kader Sebagai Pendamping Keluarga Ibu Hamil di Puskesmas II Sumbang. Jurnal Kesmas Indonesia Vol 10 No 1. Hal 13-27
Nursiswati, Rafiyah I dan Sutini T, 2015. Pemberdayaan Kader Kesehatan dalam Program "Self Care Management" Penderita Diabetes Melitus di Desa Mekarwangi dan Bendungan Kecamatan Pagaden Barat Kabupaten Subang.Jurnal Aplikasi Ipteks untuk Masyarakat.Vol. 3, No. 1, Mei 2014: 13 - 15

Pusat Data dan Informasi Kementerian Kesehatan Republik Indonesia. 2014. Waspada Diabetes.

Riset Kesehatan Dasar. 2013. Jakarta : Badan Penelitian dan Pengembangan Kesehatan Kementerian Kesehatan RI.

Sari CWM, Yamin A, dan Sari SP, 2018. Edukasi Berbasis Masyarakat untuk Deteksi Dini Diabetes Melitus Tipe 2. Jurnal MKK Vol 1 No 1 .

Supit J, Massi G, dan Kallo V, 2018. Efektifitas Pemberian Edukasi dengan Metode Video dan Focus Group Discussion (FGD) terhadap Tingkat Pengetahuan Pasien DM Tipe 2 di Klinik Diabetes Kimia Farma Husada Manado.Jurnal Keperawatan Vol 6 No 1 .

Surya R, Mulyadi, dan Usman S, 2017. Konseling Terhadap Peningkatan Pengetahuan Pasien Diabetes Mellitus (DM) Tipe 2 Counseling To Increase Patient Knowledge With Diabetes Melitus (DM) Type 2. Jurnal Ilmu Keperawatan ISSN: 2338-6371 